\title{
English Language Proficiency and Employability of University Students: A Sociological Study of Undergraduates at the Faculty of Arts and Culture, South Eastern University of Sri Lanka (SEUSL)
}

\author{
A. Rameez ${ }^{1}$ \\ ${ }^{1}$ Senior Lecturer in Sociology, Department of Sociology, South Eastern University of Sri Lanka, Oluvil, Sri \\ Lanka \\ Correspondence: A. Rameez, Department of Sociology, South University of Sri Lanka, Oluvil, Sri Lanka. E-mail: \\ arameez@seu.ac.lk
}

Received: December 16, 2018 Accepted: January 19, 2019 Online Published: February 24, 2019

doi:10.5539/ijel.v9n2p199 URL: https://doi.org/10.5539/ijel.v9n2p199

\begin{abstract}
Gaining mastery over the English language by undergraduates of universities has acquired much significance today because it plays a significant role in ensuring their future employability. This is highly relevant to the students of the Faculty of Arts and Culture (FAC), SEUSL, as a majority of them are from rural areas and pursue their degrees in the Tamil medium. Results of English language examinations held in recent years at the faculty indicate the poor command of English language of undergraduates, and the trend appears to be set firmly. Thus, the objective of this study is to explore the factors contributing to the poor performance of students in English language and to examine the ways in which this problem could be addressed. This is a qualitative study consisting of observation, interviews and focus group discussions employed as techniques of data collection. The study argues that the enrolment of students from rural background, psychological dimension of students, and the lack of reading habit among them are the key factors responsible for their poor level of English knowledge. Lack of physical resources such as visual aids, lack of learner centered teaching (LCT) method, and inexperienced teaching panel are also highlighted as additional factors contributing to the poor command of the language that inevitably leads to poor employment prospects for graduates after they pass out. Therefore, this study suggests that the prevailing trend can be reversed by enhancing the students' self-confidence and changing their attitudes so they will be motivated to learn the language willingly; upgrading the physical as well as human resources available to students in the faculty will provide an additional impetus to enhance their proficiency in English language.
\end{abstract}

Keywords: employability, inexperienced teaching panel, lack of physical resources, psychological factors, rural areas

\section{Introduction}

Although many languages are spoken around the world, English has taken the place as leading international language in the $21^{\text {st }}$ century; in fact, more foreign language speakers use English than the native English speakers (McKay, 2002). In many non-English speaking countries, children are taught and encouraged to learn English as a second language, since it has become so essential in the sphere of education, research and employment. Even in countries where English is not an official language, it is found that most science and engineering course syllabi are drafted in English, as it is deemed the dominant language of the sciences. The popularity of English language in all spheres has created a worldwide demand for people who are proficient in that language, which in turn requires non-native speakers of English to gain mastery in that language (Mehmoodzadeh, 2012).

There are many factors behind the evolution of English as a universal language: a) English is the most commonly used language for international communication as it enables people from different countries to interact with one another, b) it is the language of science and research, of aviation, computers, diplomacy, and tourism, c) English empowers people to easily choose from more career opportunities in the government or private sector in their own country or abroad, d) it is also the language of international media and the internet, which allows access to many more resources online, e) it is the language of Hollywood, entertainment and social media (Dharaji, 2017). By and 
large, a sound knowledge of English is crucial for someone who wishes to succeed in life.

Sri Lanka has a plural society consisting of Sinhalese (Buddhists) as a major ethnic group, with Tamils (Hindus) and Muslims constituting minority ethnic groups. Thus, Sinhala and Tamil languages are recognized as official languages. Nevertheless, the constitution of the country accepts English as a link language, as it is widely used for educational, scientific and commercial purposes (Note 1). Sri Lankan English prompts a lot of controversy in the academic discourses as it stands out as a distinct dialect of English (Ruiz Garido, 2010). A recent study reports that in Sri Lanka English is spoken fluently by approximately $48 \%$ of the population and that it is also the native language of approximately 74,000 people (Note 2).

\subsection{English Language at Sri Lankan Universities}

There are about 15 universities in Sri Lanka, with the medium of instruction varying from university to university. Some universities have adopted the vernacular languages of Sinhala and Tamil as the medium of instruction, while in others English is the medium of instruction. It is pertinent to note here that different faculties of the same university may use different languages as the medium of instruction. There are even instances where different departments in the faculty of a university may adopt different languages as the medium of instruction. By and large, there is no hard and fast rule as for the language used as the medium of instruction within the university system. Presently though, a strong emphasis is being placed on adopting English as the medium of instruction in all the universities to equip the undergraduates with this essential skill so they can cope better in meeting the demands of the world of work. The World Bank and other organizations have recently allocated several grants to Sri Lankan Universities not only to enhance the English competencies of undergraduates but also to shift the medium of instruction from vernacular languages to English so that the undergraduates would become employable in the job market after they graduate at the end of their studies.

\subsection{South Eastern University and the Use of English Language in the Faculty of Arts and Culture}

South Eastern University of Sri Lanka was established in 1996 with just two faculties. As a result of rapid development, it has become one of the fastest developing universities in Sri Lanka with six faculties presently, namely the Faculty of Arts and Culture (FAC), Faculty of Commerce and Management (FMC), Faculty of Islamic and Arabic (FIA), Faculty of Applied Sciences (FAS), Faculty of Engineering, and Faculty of Technology. Now it has a total of 4851 students in all of the faculties (Examination Branch of SEUSL, 2018). Faculties and departments of the university adopt either Tamil or English as the medium of instruction for each subject.

The Faculty of Arts \& Culture (FAC), consisting of seven Departments plus the Computer Unit, offers a general degree program of three (03) academic years and a few special degree programs of four (04) academic years. The faculty presently has 1043 undergraduate students representing two main ethnic groups, Muslims and Tamils. Interestingly, the proportion of female students is very high in the faculty, accounting for approximately $90 \%$ of the total student population (Examination Branch of SEUSL, 2018). The medium of instruction in the Faculty of Arts and Culture is either Tamil or English, depending on the subject.

One of the goals of the Faculty of Arts and Culture (FAC) is to enhance the students' English language competency to the level necessary to cater to the needs of employers in the job market. Yet, most of the students in the FAC, irrespective of whether they come from suburban or rural areas, are poor in English. The Department of English Language Teaching (DELT), which is attached to the FAC, plays a pivotal role in enhancing the English language skills of students.

Despite all the efforts taken to improve the standard of English among undergraduates at the Faculty of Arts and Culture, their competency in English language remains rather poor; thus, they have a hard time finding employment in the job market upon their graduation.

Although there is a flood of literature on the substantial amount of work done to improve the standard of English of undergraduates in the university system (Nawaz, 2012, 2013, 2016; Premawardhena, 2007; McKay, 2002; Mehmoodzadeh, 2012; Harun, 2009; Azeera et al., 2016), scholarly works on the English language proficiency of undergraduates representing the Faculty of Arts and Culture is rather limited. The researcher feels that it is necessary to assess the present English language aptitude of students at the Faculty of Arts and Culture (FAC) at the South Eastern University of Sri Lanka (SEUSL) and explore the challenges that must be addressed to raise the poor standard of English language among its undergraduates. Therefore, the main objective of this study is to explore the factors contributing to the poor performance of students in English language and examine the ways in which this problem could be addressed. 


\section{Method}

\subsection{Research Design}

This is a qualitative study in which observation, in-depth interviews and focus group discussions are employed as techniques of data collection. Moreover, secondary data were collected from existing literature relevant to this theme, journal articles, research reports, newspaper reports, website articles, and so on.

\subsection{Participants}

25 students and 5 staff members were involved in the in-depth interviews for the study, while 12-15 students, including males and females, representing each year of study in the various courses of the faculties were selected to participate in the two Focus Group Discussions held at the faculty. All of these participants/ students were engaged in learning English as a second language.

\subsection{Techniques}

During the first stage of qualitative data collection, 25 in-depth interviews were conducted with undergraduates of the FAC, SEUSL. Selection of respondents for the interviews was based on random sampling method and both males and females following each year of the course were considered for the interview. In addition, 5 interviews were conducted with the staff teaching English and also other courses in the faculty. These respondents too were selected according to the random sampling method.

Only two (02) Focus Group Discussions (FGDs) were conducted with the students, but they represented all years of study. Factors that contributed to the poor performance of English knowledge of the undergraduates and suggestions to reverse this trend were the main topics of investigation during the in-depth interviews and FGDs conducted with students and staff of the faculty.

In addition, careful observation was another technique that was purposefully and systematically employed during the data collection process to assess the level of English language competence of students.

\subsection{Data Collection Procedure and Data Analysis}

The data were collected by posing questions about the English language experiences of students and the factors contributing to low competence in the language using a snowballing method, with interviews and FGDs employed as techniques for this study. Before commencing the interviews and FGDs, participants were informed about the purpose of the study and were assured of the confidentiality of their disclosures with respect to their responses to the questions. To increase the reliability of answers, the author explained each question clearly to the students so they would comprehend it better.

Qualitative data were analyzed using the descriptive method, supported by tables, graphs and pie charts.

\section{Findings and Discussion}

This section contains the findings related to competency in English language of students reading for their undergraduate studies at the Faculty of Arts and Culture, SEUSL, and the factors contributing to the poor English language competency of students.

\subsection{Competency of Students in English Language at Faculty of Arts and Culture}

The Faculty of Arts \& Culture (FAC) has a total of 1043 students pursuing their undergraduate studies at present. Of these, 324 students are in the first year, 356 students in the second year, 271 students in the third year, and 92 students in the fourth year. In general, the proportion of female students is very high compared to the number of male students, whatever the year. Out of 1043 students, only 113 students are male, which means that $90 \%$ of students in the faculty are female (Faculty records, 2018). It should be noted that the number of male students has been decreasing gradually every year.

Department of English Language Teaching (DELT) offers compulsory two-credit courses for internal students each semester over a period of three years (six semesters). The titles of the courses are, Elementary, Pre-intermediate and Intermediate English for all first, second and third year students, respectively. These courses are aimed at equipping the students with a higher level of English skills to prepare them for the world of employment. DELT conducts intensive English courses for all the new entrants. The students are divided into different groups based on their performance in the English placement test conducted at the beginning of the course and then the English courses are conducted accordingly.

More importantly, the examination results of English Language competency conducted by the Faculty of Arts and Culture indicate the present level of English proficiency of students. 
Table 1. Present level of English proficiency of FAC students

\begin{tabular}{|c|c|c|c|c|c|c|}
\hline Year of study & $\begin{array}{l}\text { Number of } \\
\text { students who } \\
\text { sat for the } \\
\text { exam in } \\
\text { Semester I in } \\
2015 / 2016\end{array}$ & $\begin{array}{l}\text { Number of } \\
\text { students who } \\
\text { passed in English } \\
\text { Language in } \\
\text { Semester I in } \\
2015 / 2016\end{array}$ & $\begin{array}{l}\text { Number of students } \\
\text { who Failed in } \\
\text { English Language } \\
\text { (Obtained "D, D+ } \\
\text { and C-" Passes) in } \\
\text { Semester I in } \\
\text { 2015/2016 } \\
\end{array}$ & $\begin{array}{l}\text { Number of } \\
\text { students who } \\
\text { sat for the } \\
\text { exam in } \\
\text { Semester II in } \\
2015 / 2016\end{array}$ & $\begin{array}{l}\text { Number of } \\
\text { Students who } \\
\text { passed in } \\
\text { English } \\
\text { Language in } \\
\text { Semester II in } \\
2015 / 2016 \\
\end{array}$ & $\begin{array}{l}\text { Number of students } \\
\text { who Failed in } \\
\text { English Language } \\
\text { (Obtained "D, D+ } \\
\text { and C-" Passes) in } \\
\text { Semester II in } \\
\text { 2015/2016 }\end{array}$ \\
\hline First Year & 349 & 307 & 42 & 347 & 299 & 48 \\
\hline Second Year & 249 & 197 & 52 & 249 & 201 & 48 \\
\hline Third Year & 209 & 171 & 38 & 209 & 157 & 52 \\
\hline Fourth Year & 69 & - & - & 53 & - & - \\
\hline Total & 876 & 675 & 132 & 860 & 657 & 148 \\
\hline
\end{tabular}

Source: Examinations Branch, SEUSL, 2018.

Table 1 indicates that the number of students failing the English Language examination conducted by the FAC is steadily increasing in all years of the study course. While the total number of students who failed the English Language test in semester I stands at 132 out of the 876 students who sat for the exam, the total number of students who failed the English Language test in semester II stands at 148 even though a fewer number of students (860) sat for this examination. This indicates the poor trend in English proficiency of students in the faculty. This can be compared with the findings of a study showing that out of 180 students who sat for the first year, first semester English examination at the Faculty of Applied Sciences, South Eastern University of Sri Lanka, two-thirds had failed the examination (Nawaz, 2016a). Although this finding is from another faculty of the same university, this result too provides some insight into the current issue of poor English language proficiency of students.

The non-state sector as well as the state sector places much emphasis on English language skills when recruiting graduates because they consider that employees having a good knowledge of English language with ability to communicate in that language will be a big asset to their organization. Therefore, it is essential for graduates to enhance their competence in English so that they can immerse themselves in their work confidently and perform much more effectively. Especially, at a time when those who studied Humanities and Social Sciences have a hard time finding employment in the job market after graduation, much emphasis needs to be laid on the enhancement of their English language skills and Soft-Skills Development such as critical thinking, problem solving skills, leadership skills and so on.

An online survey conducted in 2017 among graduates of the 2011/2012 academic batch of FAC, SEUSL, a year after they passed out in 2016 indicated that out of the total of 345 graduates, of whom 59 were male and 286 female, only 29 graduates representing 5 males and 24 females had found jobs in the government and private sectors (Faculty records, 2017). This suggests a poor track record of employment secured by FAC graduates of SEUSL. The Survey showed that one of the major obstacles the students faced in finding employment was their lack of sufficient knowledge of English. Whereas English language proficiency is a prerequisite for graduates to secure employment in the job market, recent trends suggest poor development of English language competency among the graduates of FAC, SEUSL. This will in turn, have dire consequences on their future prospects, including their employability and social status in society. This study was undertaken for this reason, in order to explore the key factors contributing to the poor English language skills of the undergraduates of FAC.

\subsection{Factors Contributing to the Poor Standard of English of Students}

This section discusses the factors contributing to the low proficiency in English of respondents that was identified during the in-depth interviews and FGDs.

\subsubsection{Rural Background of Students}

The written and spoken English of the rural students is considerably poorer than that of the urban group. This is primarily due to the poor occupational status of their parents and the learner's proclivity for watching only entertainment programs at the regional level (Sankary, 2007). Majority of the students enrolling in the degree program at FAC, SEUSL have either come from suburban or rural areas and had difficulties in learning the English language due to the lack of proper coaching throughout the course of their school career. As such, it appears that the students had not realized the importance of the English language until they enrolled in the university or later approached the job market seeking good positions. It is reported that English language 
proficiency of nearly half the students in the faculty is inadequate to get them a passing grade of forty marks (40\%). Lack of proficiency in English language is attributed to their rural background and the poor quality of English teaching that prevailed at school level (Nawaz, 2016b). The situation might have been different if they had received a relatively good foundation in the English language at the school level. It is noteworthy that a pass in English is not compulsory at the G.C.E. Ordinary Level (O/L) or G.C.E. Advanced Level (A/L) examination. Therefore, the students have no problem in entering a university in Sri Lanka even in the case of a student who has failed to get a pass in General English at the G.C.E. $(\mathrm{O} / \mathrm{L})$ or $(\mathrm{A} / \mathrm{L})$ examination. If the university made it a compulsory requirement to have a pass in English at both $\mathrm{O} / \mathrm{L}$ and $\mathrm{A} / \mathrm{L}$ examinations, students would have performed well as they would have no alternative but to learn the language. The findings show that students who were planning to enter university were not properly updated on the compulsory need for English language to successfully complete the degree. Respondents of interviews contended that students selected to the Faculty of Arts and Culture, SEUSL had an impression that their courses would be conducted in their vernacular language, that is, in Tamil medium at the university and therefore, they had no need to master the English language. One of the students observed:

"We pursued our studies from primary class to Advanced Level at school in Tamil medium. We took English for granted during our school period. We did not know that it would be a compulsory course at the university, until we came here. If we had known it, we would have taken the extra effort to learn the language" (Interview 1).

Thus, the students contended that had they known of the compulsory requirement for English as an auxiliary course at the university to complete their degree, they would have somehow taken greater effort to learn the language well. This indicates their ignorance and carefree attitude at the time of their studies at school. Majority of the academic staff I interviewed also attribute the poor standard of English among the students in the faculty to their rural background. One of the staff view:

"These students are coming from poor rural background and thus they have had no proper English background. Actually, this is a major problem of students enrolling for the course at our faculty in respect of English proficiency" (Interview 11).

All of these indicate students enrolling in the degree program at the faculty from rural background have significant problems in terms of their English proficiency.

\subsubsection{Psychological Dimensions}

It is a flawed but pervasive impression amongst students that English is the most difficult of all subjects. Hence, most of the students look upon this subject with dread and carry the fear through the years. Their worry and depression results in poor performance at the end of the year. This can be corroborated by the findings of a study that reports that students have a perception that English is hard to learn and thus they feel shy to pose questions during classes (Nawaz, 2016a). A large number of students, particularly female students in the faculty have an uneasiness or phobia about English. Most important problem faced during lecturer-student interaction is shyness and fear of speaking the language in public (Nawaz, 2013). The students are also concerned that lecturers may penalize them for posing questions during lectures or they assume that asking questions may be considered as challenging the authority of the lecturers (Ibid, p. 133). Fear and shyness are major problems confronting students at lectures in the matter of requesting clarifications (Harun, 2009). As such, the students remain pessimistic and are subject to a negative impression that learning English language is the most difficult task in the world. Thus, this prompts one to explore ways and means of ridding them of any phobia about English and make them understand that English is simply a tool of communication that they need to learn and use. One student observed:

"We realized the importance of English soon after coming to the university. However, we fear the language and are shy to talk in English. We feel bad when some of our friends tease us when we start talking in English" (Interview 2)

This perception underscores the fact that not only do students have a phobia about English, they are also highly concerned about drawing negative comments from their colleagues when speaking English in public. This culture of undermining others for speaking in English or any other language in public is detrimental to those who are learning, especially university students like those at FAC, SEUSL.

Responses of students also suggest that a majority of them who attend English language classes conducted by the faculty have a negative attitude regarding the language. They mostly attend the English classes reluctantly and with a lethargic attitude, and mainly because of the compulsory $80 \%$ attendance requirement for lectures to sit for the final year examination at the end of semester. One of the teachers in the faculty expressed her views: 
"Students have no genuine interest in learning the language properly; they attend the language classes simply to pass the subject and complete their degree. If the $80 \%$ attendance at lectures was not a compulsory requirement, most of them would have failed to attend the English classes regularly" (Interview 10)

This shows the mentality of students; their outlook is short-sighted, in that they want to pass the English examination only for the purpose of successfully completing the degree. Although a few students were passionate about mastering the language, it is pertinent to note that the majority of them have not realized the significance of English language during their studies at the university. They eventually grasp the importance of English language only after their graduation when they go out seeking jobs. But in the world of the job market, proficiency in English is what opens the door to job opportunities. Therefore, the students should be encouraged to learn English not only by their teachers and colleagues, but also by their parents and family members. Thus, social institutions such as school, family and neighbors bear much responsibility upon their shoulders in trying to change the attitude of students toward the English language.

\subsubsection{Lack of Reading Habit}

It is well-known that reading is a very good habit that can make any person more knowledgeable through the acquisition of a great deal of information, which can prove very useful in this modern, hi-tech world. Language can be learned not only through professional coaching, but by self-learning and reading, as well. Poor reading habits of undergraduates at the South Eastern University have reduced the proficiency of students in English language to an unacceptable level (Azeera et al., 2016). Students at the interviews acknowledged that their poor reading habits in respect of English material like books, journals and magazines seriously undermined their competency in that language. One student's views:

"We learn most of the subjects in Tamil medium and so we look for material written in that language at the library and other places. Therefore, we have little time to read English material and so we hardly make any use of it" (Interview 3)

The following is a similar view expressed by an academic staff serving in the faculty in respect of reading habit of students.

"As students read their courses in Tamil medium, they have no genuine interest in furthering their knowledge and proficiency of English language. However, it is common that they become aware of this pitfall once they go to the job market at the end of their graduation" (Interview 12)

It will be readily appreciated that since the medium of instruction is Tamil, the students devote much of their time reading materials/ documents written in Tamil. Thus, they can spare only a little time to read materials in English. This is one of the key factors for the poor competency of students in English language. Their competency in the language would have been much higher if they had in addition to learning English in the classroom, spent more time reading study materials, documents and books in English at the university. A study reports that reading is one of the most effective practices for enhancing the language competency of students (Dharaji, 2017). Therefore, it is essential that students of the faculty spend more time reading English materials, whether at the university or at home.

\subsubsection{Lack of Physical Resources Including Visual and Technical Aids}

Physical layout or organization of the classroom is one of the most important factors having a bearing on the success of English learning (Dharaji, 2017). Use of multimedia to play songs, movies, TV series, and read magazines can play a pivotal role in improving the language skills of students (Mohire, 1989). Integrating technology with teaching methods will create an interactive and healthy learning environment for students (Farook \& Soomro, 2018). The students who find themselves in an English speaking environment will learn the language much faster than those students who are not exposed to such an environment. In another study, it was noted that a majority of students were willing to learn English with the aid of computers, because they strongly believed that computers will provide them more scope to practice English (Mamun, 2008). It was noted in this study that a self-access center has been set up in the faculty with 10 computers within the Department of English Language Teaching (DELT). This will provide the students ready access to language learning through the use of visual aids. However, the responses of students indicate that most of them do not make use of this facility. Majority of them said they had never been to the self-access center or smart class setup with visual aids to learn English language. A third year student reading for the General Degree program made this observation:

"We don't know where the self-access center of English language is located in the DELT and have never been to it. Goodness, this is the first time I have heard about it in my university life" (Interview 4)

It is true that the self-access center and smart classrooms for teaching English in the faculty are limited, but it 
must be emphasized that the students have easy access to English language materials online for self-learning. Thousands of video clips are available on YouTube on learning English by means of which students may be able to learn something useful and brush up their language. Therefore, it needs to be noted that though there are lapses on the institutional side in not being able to provide sufficient facilities to teach English language to students, there are faults on the students' side too, because they do not invest much effort into self-learning.

\subsubsection{Lack of Learner-Centered Teaching}

It is becoming increasingly evident now that teacher-centered education needs to be re-evaluated completely, because it leads to passive behavior of students. A study reports that emphasis on teacher dominance and teacher-centered coaching in classrooms have led to passive behavior of students (Premawardhena, 2007). If this trend persists, it can be assumed that students will be passive learners after they enter the universities too. To remedy this trend, some scholars recommended that a model of Learner-Centered Teaching (LCT) be adopted in the classroom nowadays. One of the staff serving in the faculty observes:

"Learner-centered Teaching is highly emphasized by program reviewers and other experts in order to ensure the engagement and participation of students in the class room activities. This shapes students' behavior and personality too" (Interview 11).

In the model of LCT, students have plenty of opportunity to learn in numerous ways and are guided by various pedagogical methods to learn a lesson. LCT also provides a solid platform for students to engage with teachers/ instructors through a bottom-up approach instead of a top-down approach. This also liberates students by not forcing them to be solely dependent on the teachers to learn the language. In a study conducted at the Faculty of Science, SEUSL, in respect of courses conducted in the English medium, it was found that the lecture delivery mode was mostly in the nature of a monologue (Nawaz, 2012). It is generally assumed that lecturer-student interaction provides more space for students to engage in discussions in the classroom and that this would improve students' comprehension and language development (Ibid: 1-2). Such interaction between teacher and students and among the students themselves in the classroom is considered significant not only for creating a suitable learning environment, but also to develop learners' abilities and communication skills in the second language (Hall \& Verplaetse, 2000). Therefore, interaction between students and teachers in the classroom is an essential component in enhancing the language prowess of students. The Quality Assurance and Accreditation Cell established at the University Grants Commission of Sri Lanka now places much emphasis on the Outcome Based Education and Learner Centered Teaching (OBE-LCT) model. Unfortunately, the findings show that English classes in the faculty are primarily teacher-centered and continue to follow the traditional way of teaching most of the time, even though students are divided into groups based on the marks they obtained in the selection test. A student observes:

"It is good that we are divided into groups based on our proficiency in the English language. However, how is it that the instructors/ lecturers distributed the same hand-outs to students in the different groups and began teaching? In fact, they should have given different hand-outs to the different groups based on their level of competence" (Interview 5)

This shows that the methodology of teaching requires complete revamping and should be designed to give priority to learner centered teaching.

\subsubsection{Inexperienced Teaching Panel}

A study reports that an effective method for teaching English would consist of the following elements: a) group discussion, b) individual presentation, c) brainstorming, d) role play, e) conducting seminars, workshops and conferences, and f) effective lectures by experienced panel of teachers (Dharaji, 2017). These methods will facilitate the students to learn English better. More importantly, teaching of a subject/ course by professors or senior lecturers has always been more effective as compared to the same tasks being performed by juniors. It seems quite clear that seniors have a greater potential for reaching out to students than the junior level teachers. The findings suggest that mostly the junior level teachers/ lecturers are assigned to teach English in the faculty, and according to the view of students this has proved ineffective. These teachers lack experience and expertise in the art of teaching, particularly in English language, and behave aggressively with students in the classroom. One of the students said,

"Most of the assistant lecturers (juniors) teach us English and they happen to be our super seniors in the university too. They lack experience and skill in teaching; they are aggressive and tough and show no flexibility; their expectation of students is high. We have never been taught English courses so far by senior or permanent lecturers yet" (Interview 6) 
The above responses of students are self-explanatory. However, the assertion that senior teachers never delivered English lectures was disputed by some students during the focus group discussion; they pointed out that they have been taught by a senior lecturer. However, they said that other sets of students in the same year of study are being taught by junior lecturers. Further, a student contended that,

"It is disheartening to inform that the contents of the English course remain the same. We were taught about 'adjective' and 'adverb' during the intensive course given in the first year. Sadly, we are still being taught the same subject matter (adjective and adverb) in the third year of our program, when we are nearing the completion of our studies. Moreover, we have no course on spoken English or working English in the syllabus" (Interview 7)

The above response referred to a very important point made during the discussion. The syllabus of English courses needs to be revised and well-designed to cater to the needs of students. In addition to assigning senior teachers to teach English to students, special effort must be directed to brush up the English speaking capabilities of students. These efforts will definitely make the difference and most of the students will be interested in brushing up the English language. The findings show that priority has to be given to introduce a course on spoken English or working English. It is essential to introduce a course on "Working English" or "Working Knowledge of English" for students since the majority of students come from rural areas and pursue their studies in Tamil medium in the faculty. Introducing such courses will ensure that more number of students attend the lectures with much interest and perseverance. Thus, a training course to sharpen their speaking ability in English without fear or hesitation is an important task that the teachers of English must focus on soon. At the end of the day, all these efforts will ensure the employability of students at the job market at the end of their studies.

Responses obtained from 30 interviews with students and staff of the faculty can be seen in Figure 1.

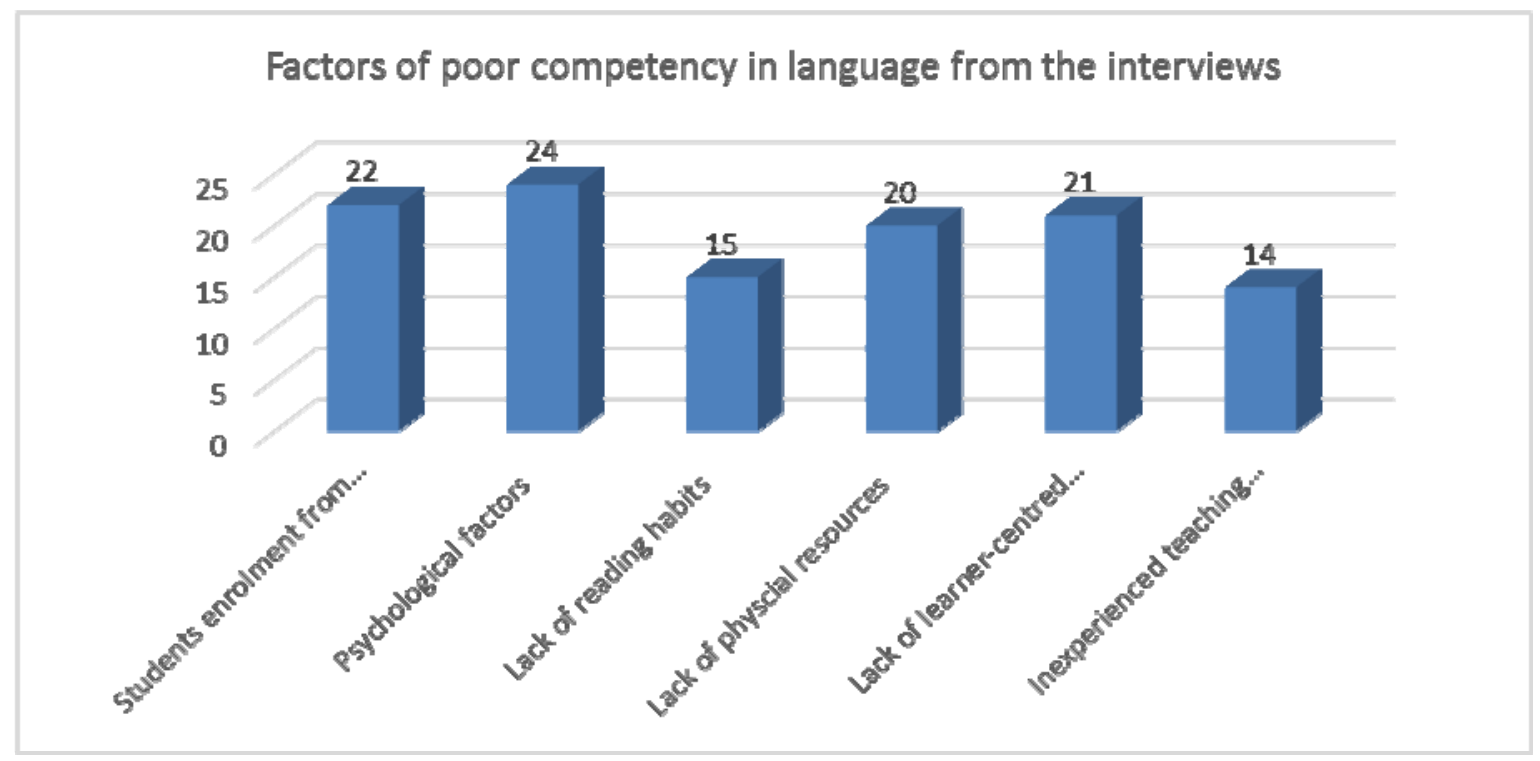

Figure 1. Factors responsible for poor competency in English language

The above figure identifies and compares the factors contributing to the poor proficiency in English language of students in the faculty. It shows that psychological factors figure prominently among all the factors with 24 respondents out of 30 indicating that it is the key factor responsible for poor competency in language by the students. Enrolment of students from rural areas, lack of learner-centered teaching, and lack of physical resources are indicated as the other significant factors behind poor performance, while lack of reading habit and inexperienced teaching panel are cited as less significant factors. By and large, all these factors together contribute significantly to the poor English language competency of students, which in turn compromises their employability even after their graduation.

\section{Conclusion}

Since English is the most common international language, it is spoken by a large number of people, regardless of ethnicity, class, religion and nationality; therefore, the need to master this language has assumed a very high priority in the contemporary world. This is very important for the students who pursue their studies at the 
university because English serves as the stepping stone that will ensure their future employment in the world of work upon their graduation. This is particularly relevant to undergraduates of the Faculty of Arts and Culture reading for their degree courses in the Tamil medium. Majority of students enrolled in the faculty are from a rural background and thus it is very essential for the FAC to produce graduates who have a good working knowledge of English.

The findings show that many students enrolling in the faculty are from rural areas. Some psychological factors and failure to read any written materials are attributed for the poor performance of these students in the English language. I agree that these are issues on the part of students who are attempting to learn the English language. However, these are not the only obstacles the students in the faculty are facing with regard to learning English. They are also put at a disadvantage by the lack of physical resources such as visual aids, lack of learner-centered teaching (LCT), and inexperienced English teaching panel leading to poor proficiency in English language. I find that these are issues arising directly from deficiencies on the part of the institution.

While it is important to boost the self-confidence of students by changing their attitudes toward learning the language, it is equally important for the faculty/ university to ensure that the senior academics teach them English, introduce learner-centered teaching in the classroom, and provide self-access centers and smart classrooms with visual aids to enhance the English proficiency of undergraduates at the faculty. At present, due to their poor English, students face much difficulty and a hard time in finding job opportunities in the world of work after they graduate. It is suggested that introducing a course on "Working English" will help students to brush up their command of the language. It is also a paramount responsibility on the part of social institutions like schools, family and neighbors to take initiatives to motivate the students and bolster their self-confidence by providing a good environment that will enable them to speak in English without fear or shyness. This will reverse the poor proficiency of English of students at the faculty, prepare the students to be competitive in the job market in future and ensure their employability.

More importantly, English should be made a compulsory subject in the $\mathrm{O} / \mathrm{L}$ and $\mathrm{A} / \mathrm{L}$ examination so that students will put in the utmost effort to learn the language, and this will come in handy in the future by enhancing their employment prospects. However, this has to be done at the policy planning level by the higher authorities in the government educational sector.

\section{References}

Alptekin, C., \& Alptekin, M. (1984). The Question of Culture: EFL teaching in non-English speaking countries. EFL Journal, 38(1), 14-20.

Azeera, A. L. F., Nizla, M. L. F., \& Kareema, M. I. F. (2016). Common Drawbacks Encountered in Learning English Language among the Undergraduates of Eastern Province. $6^{\text {th }}$ International Symposium, Oluvil, South Eastern University of Sri Lanka.

Batstone, R. (1995). Product and process: Grammar in the second language classroom. In M. Bygate, A. Tonkyn, \& E. Williams (Eds.), Grammar and the Language Teacher (pp. 224-236). London: Prentice Hall.

Chidambaram, K. (2004). A Study on the Learning Process of English. Ph. D Thesis, Department of Linguistics, Bharathiar University, Tami Nadu, India.

Crystal, D. (1997). A Dictionary of linguistics and phonetics (5th ed.). London: Blackwell Publishing.

Dharaji, H. N. (2017). A Study of Methods of Teaching English at Higher Secondary Level. Unpublished Master Thesis, Solapur, Solapur University.

Farook, M. U., \& Soomor, A. F. (2018). Teachers and Technology: Trends in English Language Teaching in Saudi Arabia. International Journal of English Linguistics, 8(5), 10-19. https://doi.org/10.5539/ijel.v8n5p10

Hall, J. K., \& Verplaetse, L. S. (Eds.). (2000). Second and Foreign Language Learning through Classroom Interaction. Mahwah, NJ: Lawrence Erlbaum. https://doi.org/10.4324/9781410605498

Harun, R. N. S. R. (2009). Understanding learners' participation in an ESL classroom: A socio-cultural perspective. English Language Journal, 3, 9-26.

Karunaratne, I. M. (2003). Teaching English in Urban Sri Lanka: Some pedagogical issues, 9th International conference on Sri Lankan studies.

Kumaravadivelu, B. (1991). Language-learning task: teacher intention and learner interpretation. English Teaching Journal, 45(2), 98-107. https://doi.org/10.1093/elt/45.2.98 
Mamun, A. B. (2008). Students Attitude towards Using Computer for Language Learning a Survey. English language Teaching Journal, 46(2), 32.

McKay, S. L. (2002). Teaching English as an international language. Oxford, UK: Oxford University Press.

Mehmoodzadeh, M. (2012). Investigating foreign language speaking anxiety within the EFL learner's inter-language system: The case of Iranian learners. Journal of Language Teaching and Research, 3(3), 466-476.

Mohire, V. N. (1989). A Critical Analysis of Methods and Means of Teaching English applied at the Undergraduate Level. In J. P. Sharma (Ed.), Fifth Survey of Educational Research. New Delhi: NCERT.

Nawaz, A. M. M. (2012). Lecturer-Student Interaction in English-Medium Science Lectures: An Investigation of Perceptions and Practice at a Sri Lankan University where English is a Second Language. Doctoral Thesis, The University of Nottingham.

Nawaz, A. M. M. (2013). A Study on Perception of Lecturer Student Interaction in English Medium Science Lectures. Novitas-ROYAL (Research on Youth and Language), 7(2), 113-136.

Nawaz, A. M. M. (2016a). Challenges Faced by Students in English Medium Undergraduate Classes: An Experience of A Young University in Sri Lanka. Journal of Arts, Science and Commerce, 7(4), 158-166.

Nawaz, A. M. M. (2016b). English Medium undergraduate classes: Are they useful for students' language development? South Eastern University Arts Research Session (SEUARS), FAC, SEUSL.

Nawaz, A. M. M. (2016c). Enhancing the Writing Skills of Weak Undergraduates: An action research conducted at South Eastern University of Sri Lanka in A collection of Research Papers from the Sri Lankan Context. Colombo: British Council.

Premawardhena, N. C. (2007). Integrating literature into foreign language teaching: A Sri Lankan perspective. Novitas-ROYAL (Research on Youth and Language), 1(2), 92-97.

Ruiz-Garido M. F. (2010). English for Professional and Academic Purposes. Utrecht studies in language and communication, 22, 21.

Sankary, D. (2007). The Rural- Urban Divide in ESL Proficiency a Myth or a Fact? English language Teaching Journal, 45(3), 20.

Verplaetse, L. S. (2000). Mr. Wonder-ful: portrait of a dialogic teacher. In J. K. Hall \& L. S. Verplaetse (Eds.), Second and Foreign Language Learning through Classroom Interaction (pp. 221-241). Mahwah: Lawrence Erlbaum Associates.

\section{Notes}

Note 1. The details are available in the Official Languages Website: http://www.languagescom.gov.lk/about_us.htm

Note 2. The report is available here: https://www.ef.com/epi/regions/asia/sri-lanka

\section{Appendix A}

\section{Details of Interviewees}

1. Interview $\mathrm{No}-01$

2. Interview $\mathrm{No}-02$

3. Interview No -03

4. Interview No -04

5. Interview No -05

6. Interview No -06

7. Interview $\mathrm{No}-07$

8. Interview No -08

9. Interview $\mathrm{No}-09$

10. Interview $\mathrm{No}-10$

11. Interview $\mathrm{No}-11$

12. Interview $\mathrm{No}-12$
Second year student

Third year student

Second year student

Third year student

Third year student

Final year student

Second year student

Fourth year student

Third year student

Academic staff member of faculty

Academic staff member of faculty

Academic staff member of faculty 


\section{Copyrights}

Copyright for this article is retained by the author, with first publication rights granted to the journal.

This is an open-access article distributed under the terms and conditions of the Creative Commons Attribution license (http://creativecommons.org/licenses/by/4.0/). 